\title{
MORFOLOGIA DE CALOS DE Eucalyptus urophylla CULTIVADOS in vitro SOB CONCENTRAÇÕES DE BORO E CÁLCIO
}

\author{
Raquel Trevizam ${ }^{1}$, Gilvano Ebling Brondani ${ }^{2}$, Renata Souza ${ }^{3}$, Marcilio de Almeida ${ }^{4}$ \\ ${ }^{1}$ Eng $^{\mathrm{a}}$ Florestal, Dr ${ }^{\mathrm{a}}$., ESALQ/USP - raqueltrevizam@yahoo.com.br \\ ${ }^{2}$ Eng. Florestal, M.Sc., Doutorando em Recursos Florestais, ESALQ/USP - gebrondani@ yahoo.com.br \\ ${ }^{3}$ Bióloga, Mestranda em Recursos Florestais, ESALQ/USP - renatagvcs@ yahoo.com.br \\ ${ }^{4}$ Biólogo, Dr., Depto. de Ciências Biológicas, ESALQ/USP - malmeida@esalq.usp.br
}

Recebido para publicação: 18/12/2008 - Aceito para publicação: 06/05/2011

\begin{abstract}
Resumo
O boro e o cálcio são nutrientes essenciais para o desenvolvimento vegetal, contudo existem poucos registros da atuação desses elementos em nível nutricional. Visando avaliar possíveis implicações desses nutrientes no desenvolvimento morfológico de Eucalyptus urophylla, calos foram cultivados in vitro sob concentrações de boro $\left(0,25,50,100\right.$ e $200 \mu \mathrm{M}$ de $\left.\mathrm{H}_{3} \mathrm{BO}_{3}\right)$ e cálcio $(0 ; 3,75 ; 7,50 ; 11,25$ e 15,00 mM de $\mathrm{CaCl}_{2}$ ). $\mathrm{O}$ experimento foi conduzido no delineamento inteiramente casualizado, no arranjo fatorial (5 x 5) contendo 5 repetições. Aos 21 e 31 dias foram avaliados os calos quanto à morfologia externa e interna. Foi possível verificar que nos dois períodos avaliados as concentrações de boro e cálcio interferiram significativamente tanto na morfologia externa como na interna, resultando em respostas diretas com aspectos visuais das estruturas calogênicas. Os resultados mostraram que as combinações de $25 \mu \mathrm{M}$ de $\mathrm{B}$ com 0; 3,75; 7,50; 11,25 e 15,00 mM de Ca, aos 21 dias, apresentaram menores prejuízos ao desenvolvimento das raízes, o que favoreceu adequadamente a formação do órgão. A produção de biomassa seca foi influenciada diretamente pela concentração de boro, sendo esse efeito constante para todas as doses de cálcio estudadas e para ambas as idades avaliadas.

Palavras-chave: Alterações morfoanatômicas; calogênese; nutrição mineral; cultura de tecidos vegetais.
\end{abstract}

\begin{abstract}
Morphology of Eucalyptus urophylla callus, cultivated in vitro under boron and calcium concentrations. Boron and calcium are essential nutrients in plant development, but there are few registers of the common action of these nutrients in vegetable. In order to identify and quantify the possible implications of these micro and macronutrients in the morphogenetic development of Eucalyptus urophylla, callus were cultivated in vitro with different concentration of boron $\left(0,25,50,100\right.$ e $\left.200 \mu \mathrm{M} \mathrm{H}_{3} \mathrm{BO}_{3}\right)$ and calcium $(0$, $3.75,7.50,11.25$ e $15.00 \mathrm{mM} \mathrm{CaCl} 2$ ). The experiment was completely randomized design in factorial arrangement $(5 \times 5)$ with 5 replications. It was evaluated after $21^{\text {th }}$ and $31^{\text {th }}$ days of culture the relation of external and internal morphology. It could be verified that in two evaluations periods the combined of boron and calcium had intervened in aspects of the internal e external morphology that had caused direct answers in visual aspects of the calluses. The combinations of $25 \mu \mathrm{M} \mathrm{B}$ with $0,3.75,7.50,11.25$ e 15.00 $\mathrm{mM} \mathrm{Ca}$ in $21^{\text {th }}$ day, were less harmful of the roots favoring appropriately organ development. The production of dry matter weight was directly influenced by boron concentration and this effect was constant for all calcium concentration and for both evaluated days.

Keywords: Morphoanatomic alterations; callogenesis; mineral nutrition; vegetable tissue culture.
\end{abstract}

\section{INTRODUÇÃO}

Nas últimas décadas, tem-se verificado aumento do plantio de florestas de Eucalyptus em regiões de climas tropicais, uma vez que elas apresentam condições térmicas e de luminosidade favoráveis ao crescimento vegetal. Contudo, as características edáficas e hídricas apresentam-se como limitantes comuns nessas áreas (ALFENAS et al., 2004). De acordo com Gonçalves (2002) e Barros et al. (2005), a maioria das áreas florestadas por Eucalyptus no Brasil está concentrada sobre solos altamente intemperizados e lixiviados, portanto com baixa disponibilidade de nutrientes essenciais ao 
desenvolvimento vegetal. Dessa forma, a utilização de técnicas de micropropagação representa uma ferramenta importante no melhoramento genético e na conservação genética de materiais vegetais, mas, para a sua utilização, é necessário conhecer o efeito de diversos fatores, como a nutrição, ou seja, a concentração de determinados minerais na viabilidade dos propágulos (WATT et al., 2000; NEHRA et al., 2005; GLOCKE et al., 2006). De maneira geral, os organismos vegetais cultivados in vitro e/ou ex vitro requerem concentrações adequadas de vários elementos minerais para o seu crescimento (GRIBBLE et al., 2002). No momento em que tais concentrações tornam-se desbalanceadas, as espécies sofrem alterações metabólicas em determinada fase do desenvolvimento, resultando em sintomas visuais característicos em órgãos ou tecidos vegetais, o que consequentemente gera perdas na produtividade e na qualidade dos produtos madeireiros.

Além disso, culturas de Eucalyptus mantidas em condições ex vitro podem apresentar padrão de crescimento anormal ou retardado dos pontos de crescimento apical, morte do ponteiro terminal, encurtamento de internódios, clorose de folhas velhas, deformação da lâmina foliar, aumento do diâmetro do pecíolo e do caule, troncos tortuosos, fissuras na casca, redução da formação de flores, atraso no florescimento, desenvolvimento inadequado dos frutos e redução na produção de sementes (MARSCHNER, 1995; GONÇALVES; VALERI, 2001), caracterizando sintomas típicos de deficiência de boro (B).

Especula-se que algumas das prováveis implicações do $\mathrm{B}$ na célula vegetal relacionam-se à divisão celular, ao aumento do tamanho das células, ao transporte de carboidratos da folha para outros órgãos (MALAVOLTA, 1980) e à atuação como agente morfogenético (SPURR, 1957). Sua participação no desenvolvimento da parede celular concentra-se nas propriedades físicas e ultraestruturais de diferenciação (MATOH et al., 1992; HU; BROWN, 1994).

Comparativamente, cultivos em condições in vitro de calos de Eucalyptus sp. mantidos em meio de cultura modificado, como o MS (MURASHIGE; SKOOG, 1962), com concentrações tóxicas ou deficientes de $\mathrm{B}$, tornaram possíveis a determinação da ação do elemento em processos bioquímicos, histológicos e de desenvolvimento, evidenciando sua importância em processos metabólicos (TREVIZAM, 2001).

À semelhança, o cálcio (Ca) atua no crescimento global e desenvolvimento das plantas, mas, ao contrário do B, suas ações no metabolismo primário são mais pronunciadas. Arruda (2000) verificou, em condições in vitro, a ação de concentrações tóxicas e deficientes de $\mathrm{Ca}$ em calos de E. urophylla, sugerindo que esse nutriente atua de forma positiva sobre mecanismos bioquímicos expressos em caracteres morfológicos e morfogenéticos da espécie.

As funções do $\mathrm{Ca}$ estão relacionadas com a capacidade de coordenação, promovendo estabilidade e ligações intermoleculares reversíveis, predominantemente na membrana plasmática e na parede celular (MARSCHNER, 1995). Para Malavolta (1980), quanto maior a presença de íons potencialmente prejudiciais no meio, mais crucial parece ser o papel do $\mathrm{Ca}$ na manutenção da integridade da membrana celular. O Ca é indispensável para as regiões de crescimento (meristemas) onde se processa a divisão mitótica contínua, bem como no desenvolvimento da raiz, atuando nos processos de alongamento celular, desintoxicação dos íons de hidrogênio e divisão celular (EPSTEIN; BLOOM, 2004; TAIZ; ZEIGER, 2004).

Devido à importância desses nutrientes para os vegetais e considerando as poucas informações sobre os processos envolvendo a interação e/ou atuação desses nutrientes no desenvolvimento celular, este trabalho baseou-se na possibilidade de atuação do B e Ca na diferenciação celular. Com base no exposto, objetivou-se avaliar, aos 21 e 31 dias de cultivo, o efeito de diferentes concentrações nutricionais de $\mathrm{B}$ e $\mathrm{Ca}$ em calos de E. urophylla cultivados in vitro.

\section{MATERIAL E MÉTODOS}

\section{Origem e fonte dos explantes}

O experimento foi conduzido no Laboratório de Morfogênese e Biologia Reprodutiva de Plantas da Escola Superior de Agricultura "Luiz de Queiroz", Piracicaba, SP. Foram utilizadas sementes de E. urophylla S.T. Blake fornecidas pelo Instituto de Pesquisas e Estudos Florestais (IPEF), as quais foram catalogadas como T8A32, lote NA 416, coletadas da população base de Anhembi, SP.

As sementes foram lavadas em água corrente e detergente neutro por 2 horas, sendo em seguida transferidas para álcool etílico $(100 \%)$ por 3 segundos e então agitadas por 20 minutos em solução de hipoclorito de sódio a $70 \%(\mathrm{v} / \mathrm{v})$. Posteriormente, foram lavadas por três vezes em água esterilizada e 
deionizada e, por fim, inoculadas em frascos de vidro $(12 \times 8 \mathrm{~cm})$, com $20 \mathrm{~mL}$ de meio $(20 \mathrm{~g}$ de sacarose e $6 \mathrm{~g}$ de ágar diluídos em $1.000 \mathrm{~mL}$ de água destilada e deionizada), para a germinação em sala de crescimento em condições de temperatura $\left(26 \pm 2{ }^{\circ} \mathrm{C}\right)$ e luminosidade $\left(50 \pm 2 \mu \mathrm{mol} . \mathrm{m}^{-2} \cdot \mathrm{s}^{-1}\right)$ controladas e fotoperíodo de 12 horas de luminosidade ao dia. Os meios de cultura foram ajustados para $\mathrm{pH}$ de 5,8, com $\mathrm{HCl}$ ou $\mathrm{NaOH}(0,1 \mathrm{M})$, autoclavados à temperatura de $121{ }^{\circ} \mathrm{C}\left(\cong 1,0 \mathrm{kgf.cm}{ }^{-2}\right)$ durante 20 minutos e distribuídos em placa de Petri contendo $10 \mathrm{ml}$ do meio de isolamento.

A germinação ocorreu aos 12 dias de cultivo e aos 21 dias coletaram-se os hipocótilos, os quais foram excisados em sua porção mediana com comprimento de $5 \mathrm{~mm}$ e transferidos para o meio $\mathrm{N} 7$ (SIMOLA, 1985) suplementado com $5 \mathrm{mg} . \mathrm{L}^{-1}$ de picloram e $1 \mathrm{mg} . \mathrm{L}^{-1}$ de caseína hidrolisada, para induzir a formação de calos.

\section{Aplicação dos tratamentos}

Aos 21 e 31 dias de cultura, as estruturas calogênicas foram transferidas para o meio de cultura N7 modificado em relação às concentrações de boro $\left(\mathrm{H}_{3} \mathrm{BO}_{3}\right)$ e de cloreto de cálcio $\left(\mathrm{CaCl}_{2}\right)$ e submetidas às condições de sala de crescimento climatizada. Para o boro foram utilizadas as concentrações de 0,25 , 50,100 e $200 \mu \mathrm{M}$ de $\mathrm{H}_{3} \mathrm{BO}_{3}$, e para o cálcio utilizaram-se $0 ; 3,75 ; 7,50 ; 11,25$ e $15,00 \mathrm{mM} \mathrm{de} \mathrm{CaCl}_{2}$. A testemunha constou do meio de cultura N7 padrão, sem alterações. Realizaram-se análises morfológicas, anatômicas e da matéria seca aos 21 e 31 dias após a inoculação dos explantes (Tabela 1).

Tabela 1. Tratamentos com boro e cálcio empregados em cultura in vitro de Eucalyptus urophylla.

Table 1. Utilized boron and calcium treatments in the Eucalyptus urophylla in vitro culture.

\begin{tabular}{lcc}
\hline Tratamento & $\begin{array}{c}\mathbf{H}_{\mathbf{3}} \mathbf{B O}_{\mathbf{3}} \\
(\mathbf{\mu M})\end{array}$ & $\begin{array}{c}\mathbf{C a C l}_{\mathbf{2}} \\
(\mathbf{m M})\end{array}$ \\
\hline T1 & 0 & 0 \\
T2 & 0 & 3,75 \\
T3 & 0 & 7,50 \\
T4 & 0 & 11,25 \\
T5 & 0 & 15,00 \\
T6 & 25 & 0 \\
T7 & 25 & 3,75 \\
T8 & 25 & 7,50 \\
T9 & 25 & 11,25 \\
T10 & 25 & 15,00 \\
T11 & 50 & 0 \\
T12 & 50 & 3,75 \\
T13 & 50 & 7,50 \\
T14 & 50 & 11,25 \\
T15 & 50 & 15,00 \\
T16 & 100 & 0 \\
T17 & 100 & 3,75 \\
T18 & 7,50 \\
T19 & 100 & 11,25 \\
T20 & 15,00 \\
T21 & 100 & 0 \\
T22 & 100 & 3,75 \\
T23 & 200 & 7,50 \\
T24 & 200 & 11,25 \\
T25 & 200 & 15,00 \\
T26 (controle) & 200 & N PADRÃO \\
\hline & 200 & \\
\hline
\end{tabular}

\section{Variáveis respostas}

As análises morfológicas consistiram de 100 calos para cada período de avaliação, sendo analisado o desenvolvimento, considerando-se o tamanho, a friabilidade e as características visuais externas das estruturas calogênicas. Quanto ao tamanho das estruturas calogênicas, considerou-se o 
comprimento em centímetros como padrão para as determinações métricas. A friabilidade e as diferenças morfológicas foram avaliadas de forma visual, à medida que se destacavam dentro de um tratamento específico, e registradas por fotografia.

Para as análises anatômicas, amostraram-se aleatoriamente 5 calos por tratamento, os quais foram fixados por 48 horas em solução de Karnovsky (KARNOVSKY, 1965). Em seguida, removeu-se o ar contido nos espaços intercelulares dos tecidos por meio de uma bomba de vácuo. Após infiltradas, as amostras foram desidratadas através de soluções alcoólicas compostas de concentrações crescentes (10, $20,30,40,50,60,70,80,90$ e $100 \% \mathrm{v} / \mathrm{v}$ ), permanecendo em cada uma delas por 10 minutos. As amostras foram infiltradas a seguir em resina glicol metacrilato (Reichert-Jung ${ }^{\circledR}$ ), formando estruturas sólidas regulares. Os blocos resultantes foram seccionados a $0,5 \mu \mathrm{m}$ de espessura, através de navalhas de aço do tipo $\mathrm{C}$ acopladas a um micrótomo rotativo manual (Leica ${ }^{\circledR}$ ). Para cada bloco foram confeccionadas 100 lâminas, sendo dispostos 8 cortes anatômicos em cada lâmina de vidro. Os cortes foram corados com azul de toluidina 0,05\% em tampão fosfato e ácido cítrico (SAKAI, 1973) por 15 minutos, montados em resina sintética Entellan $\left(\right.$ Merck $\left.^{\circledR}\right)$ e cobertos com lamínulas de vidro. As lâminas histológicas foram analisadas em microscópio óptico (Zeiss-Jenemed $2^{\circledR}$ ) acoplado a câmera fotográfica (Samsung SDC-313 ${ }^{\circledR}$ ) para captura de imagens.

Quanto à análise da massa seca, os calos foram dispostos em placas de Petri e submetidos à temperatura de $60 \pm 5^{\circ} \mathrm{C}$ em estufa por 50 horas, até atingir a estabilização da pesagem. A massa fresca foi determinada pelo uso de balança analítica de precisão $(0,001 \mathrm{~g})$.

\section{Delineamento experimental e análise dos dados}

$\mathrm{O}$ experimento foi conduzido no delineamento inteiramente casualizado em arranjo fatorial (5 x 5), sendo os fatores constituídos por cinco concentrações de boro $(0,25,50,100$ e $200 \mu \mathrm{M}$ de $\left.\mathrm{H}_{3} \mathrm{BO}_{3}\right)$, cinco concentrações de cálcio $\left(0 ; 3,75 ; 7,50 ; 11,25\right.$ e $15,00 \mathrm{mM}$ de $\left.\mathrm{CaCl}_{2}\right)$ e dois períodos de avaliação (21 e 31 dias). Para tanto, utilizou-se uma testemunha adicional (N7 Padrão) e cinco repetições com 20 calos, totalizando 100 calos para cada tratamento.

Os dados amostrados foram submetidos a análise de variância (ANOVA) $(P<0,01$ e $P<0,05)$ e, de acordo com a significância, os foram submetidos a análise de regressão polinomial $(P<0,01$ e $P<0,05)$.

\section{RESULTADOS E DISCUSSÕES}

\section{Morfologia}

A omissão de B aos 21 dias de cultivo in vitro resultou em coloração mais intensa dos cortes histológicos dos calos, quando comparadas as mesmas combinações no período de 31 dias. No período de 31 dias, a deficiência de B e Ca poderia ser apontada como responsável pelas modificações nas ligações moleculares do calo, fato que possivelmente interferiu na coloração dos cortes. Moraes et al. (2002) também relacionaram a deficiência de B com a coloração menos intensa ao azul de toluidina em xilemas de caules de seringueira (Hevea sp.).

Outro fator relevante observado em calos cultivados por 21 dias foi a organização celular com a formação de meristemoides e raízes, ao passo que tempos mais longos de cultivo determinaram estruturas compostas de células meristemáticas diferenciadas em estruturas vasculares. Nas concentrações de $50 \mu \mathrm{M}$ de B combinado com 7,50; 11,25 e 15,00 mM de Ca, e de $100 \mu \mathrm{M}$ de B combinado com 7,50 e 11,25 mM de $\mathrm{Ca}$ do meio de cultura para calos de E. urophylla cultivados por 21 dias, os meristemoides apresentaram arranjos organizados compostos de células pequenas dispostas concentricamente, com aspecto isodiamétrico, sem vacúolos, com núcleos densamente corados e elevada relação núcleocitoplasmática (RPN) (Figura 1).

Ho e Vasil (1983), trabalhando com embriogênese somática de Saccharum officinarum L., classificaram esses centros meristemáticos como embrioides. Em contrapartida, considerando os resultados obtidos, podemos supor que a presença de centros meristemáticos indicam processos morfogenéticos capacitados para a indução de raízes e/ou pré-embriões somáticos.

Como não foram verificados embriões somáticos durante os dois períodos de avaliação, supõe-se que concentrações combinadas de $\mathrm{B}$ e Ca possuem a capacidade de interferir na polaridade celular, condição fundamental para a iniciação embriogenética somática. A presença de intensas divisões celulares e a grande capacidade rizogênica dos calos mantidos in vitro por 21 dias indicam a 
predominância de unipolarização da base dos meristemas, caracterizando a formação de raízes. Já aos 31 dias, a diferenciação das estruturas radiculares não foi visualmente identificada.

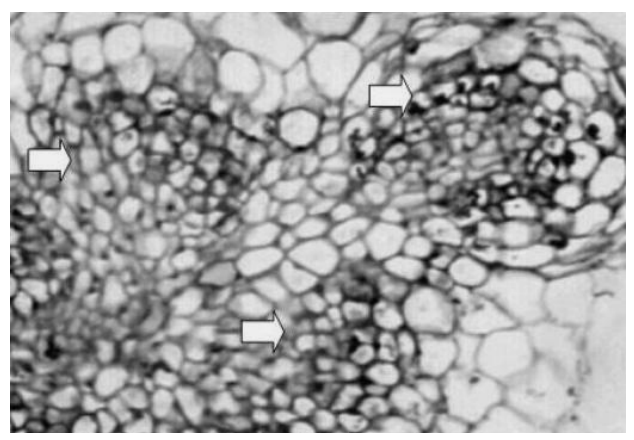

Figura 1. Aspecto geral dos meristemoides em calos de Eucalyptus urophylla aos 21 dias de cultivo in vitro. As setas indicam a presença de células pequenas e organizadas, com formatos isodiamétricos, intensas divisões nucleares e elevada relação núcleo-citoplasmática.

Figure 1. Meristemoid general aspect in Eucalyptus urophylla callus at 21 days, under in vitro cultivation. The arrows indicate the presence of small and organized cells, with isodiametrical formats, intense nuclear division and high cytoplasmic nucleus ratio.

Os cortes histológicos de calos de E. urophylla avaliados aos 31 dias apresentaram 2 tipos de diferenciação. A primeira foi verificada nas combinações de $25 \mu \mathrm{M}$ de B com todas as concentrações de $\mathrm{Ca}$ (Figuras 2A e 2B), e a segunda pode ser observada nas combinações de $100 \mu \mathrm{M}$ de B com 11,25 e $15,00 \mathrm{mM}$ de $\mathrm{Ca}$, e de $200 \mu \mathrm{M}$ de B com 11,25 e 15,00 mM de Ca (Figuras 3A, 3B e 3C).

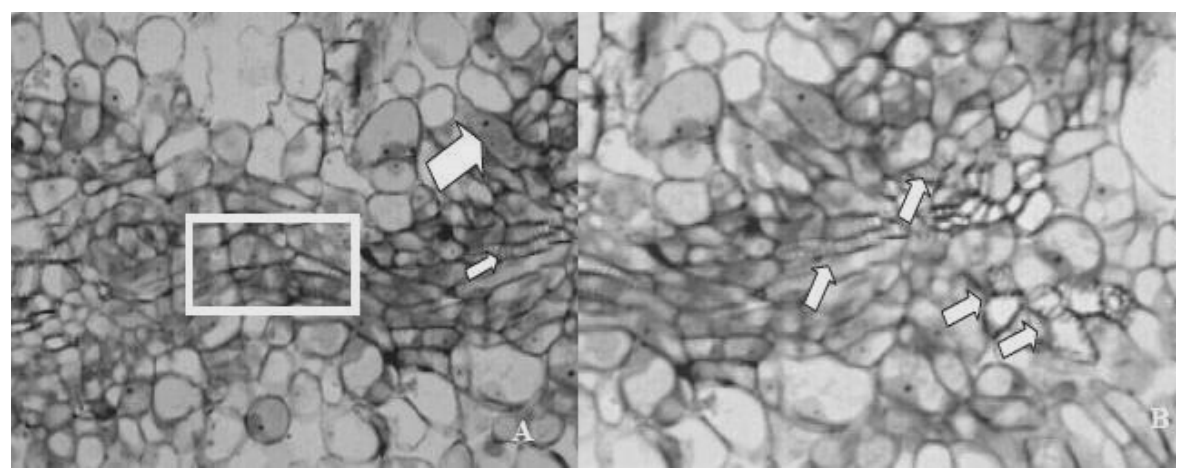

Figura 2. Aspecto geral das regiões em diferenciação dos meristemoides de calos de Eucalyptus urophylla aos 31 dias de cultivo in vitro. A. Células com baixa relação núcleo-plasmática (RNP), com diferenciação de sistema fundamental, com formas alongadas (em detalhe), núcleos proeminentes com indicação de divisão celular (seta larga) e diferenciação de sistema vascular (seta estreita); B. Detalhe de elementos vasculares do xilema (em vista longitudinal) formados isoladamente nos calos (setas).

Figure 2. General aspect of the meristemoids differentiation regions in callus of Eucalyptus urophylla under in vitro cultivation, at the 31 days. A. Low plasmatic nucleus ratio (PNR) cells, with fundamental system differentiation and elongated forms (in detail); prominent nucleus with indication of cell division (large arrow) and vascular system differentiation (small arrow); B. Detail of xylem vascular elements (longitudinal view) individually formed in callus (arrows).

Os calos que caracterizaram o primeiro tipo de diferenciação (Figuras 2A e 2B) apresentaram estruturas com células de aspecto meristemático, porém arranjadas de forma distinta ao observado para o 
período de cultivo de 21 dias (Figura 1). No maior período de cultivo, essas estruturas se mostraram organizadas em estratos com células alongadas, com núcleos proeminentes e diferenciação de sistema vascular sem a formação convencional de raízes.

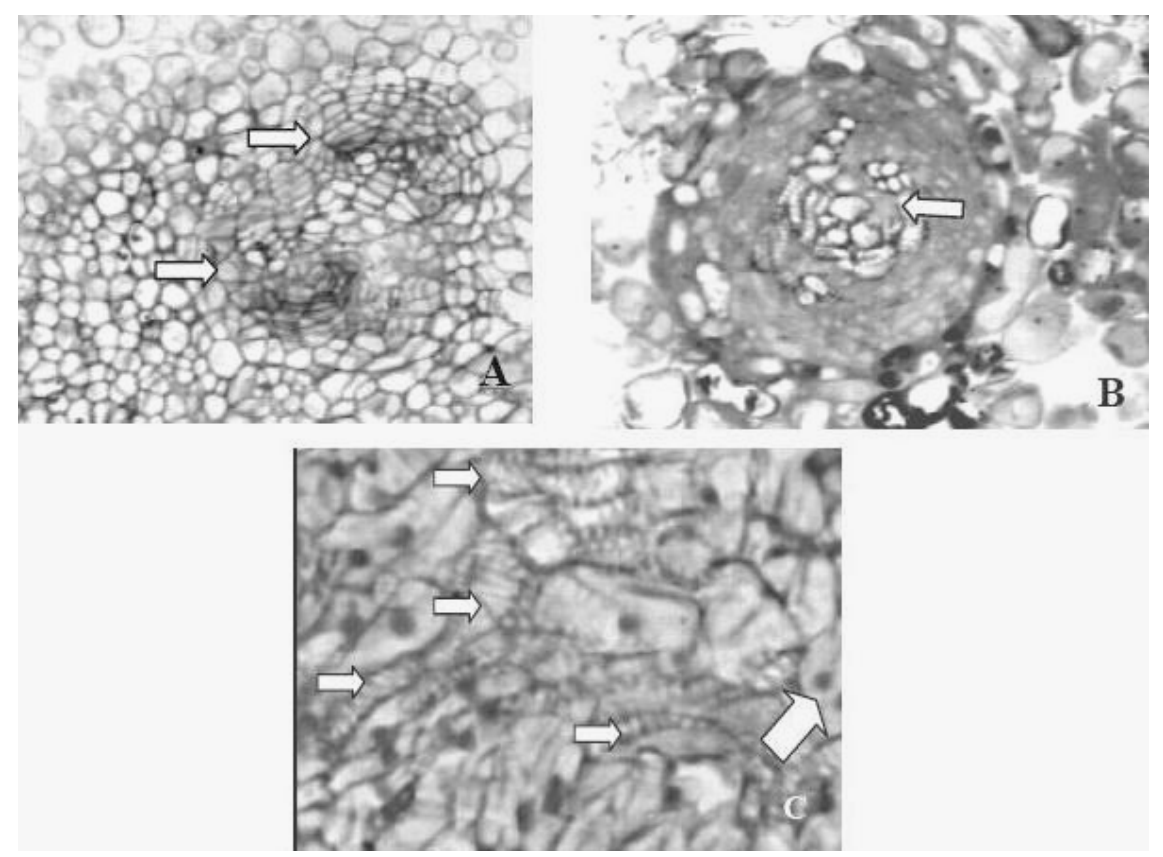

Figura 3. Aspecto geral de meristemoides com forma circular, visualizado aos 31 dias, em combinações específicas de boro e cálcio. A. Conformação circular do meristemoide bipolarizado, provável embrião somático (seta); B. Xilogênese: diferenciação de elementos de vaso do xilema no centro do meristemoide (seta); C. Detalhe dos elementos de vaso (setas estreita) e de núcleos proeminentes com presença de divisão celular (seta larga).

Figure 3. General appearance of meristemoids with a circular shape, which were visualized at the 31 days, under specific combinations of boron and calcium. A. Meristemoids circular aspect (arrow); B. Xylem differentiation in the meristemoids center (arrow); C. Xylem (small arrows) and prominent nucleus presenting cell division (large arrow) details.

A diferenciação de elementos vasculares também foi visualizada em calos de E. urophylla avaliados aos 31 dias de cultivo, nas combinações de $100 \mu \mathrm{M}$ de B com 11,25 e 15,00 mM de Ca, e de $200 \mu \mathrm{M}$ de B com 11,25 e 15,00 mM de Ca. Nesses tratamentos, os meristemoides apresentaram formato retangular (concêntrico) semelhante ao visualizado aos 21 dias (Figura 1). Contudo, os fatores diferenciais nessas estruturas deram-se pelo desenvolvimento de vasos condutores, especificamente elementos de vasos (xilogênese) sem a ligação com forma convencional de um órgão. Verificou-se que os cortes dos vasos deram-se em forma longitudinal, enquanto a estrutura meristemática mostrou-se um corte transversal.

Observou-se, ainda, que as células da periferia do calo eram isodiamétricas e com relação núcleo-plasmática elevada, revelando intensa atividade meristemática e muito indiferenciada, ao passo que as células centrais apresentaram-se alongadas, com reforço de lignina, indicando elevado índice de diferenciação para a formação de elementos de vaso (Figuras 3A e 3B).

As células meristemáticas, quando cessam a divisão, passam por um processo de diferenciação, transformando-se em células de tecidos diferenciados que compõem o corpo vegetal. O xilema e o floema em estádio primário de desenvolvimento se originam a partir do tecido meristemático do procâmbio, sendo classificados como tecidos complexos, uma vez que são os últimos a se diferenciar e contêm células de mais de um tipo de tecido (ESAU, 2000). A figura 3C apresenta vasos condutores se diferenciando a partir do meristemoide. No entanto, estudos complementares deverão ser realizados, visto que o plano de corte dos calos de E. urophylla pode ter interferido nas análises dos cortes histológicos. 
Embora sejam encontradas diversas atuações celulares do boro e cálcio, não se verificou qualquer descrição da correlação direta da interação desses dois nutrientes na gênese de elementos vasculares. A atuação de boro e cálcio em E. urophylla está relacionada principalmente com a formação e alongamento do sistema radicular. Contudo e Lewis (1980) afirma que ocorre ação primária do B durante a diferenciação do xilema. Da mesma forma, Moraes et al. (2002) constataram que os elementos do xilema recém-formados possuíam paredes primárias mais finas nas amostras de plantas com sintomas de deficiências causadas pelo micronutriente. Esse aspecto também pode ser relacionado com a coloração menos intensa dos cortes histológicos provenientes de calos cultivados com concentrações deficientes de $\mathrm{B}$ e $\mathrm{Ca}$, por 31 dias.

Neste estudo não foi possível verificar a relação dos nutrientes minerais com as paredes dos vasos condutores. Contudo, admite-se que aos 31 dias a interação do B com o Ca por meio das combinações de $100 \mu \mathrm{M}$ de B com 11,25 e 15,00 mM de Ca e de $200 \mu \mathrm{M}$ de B com 11,25 e 15,00 mM de $\mathrm{Ca}$ foram responsáveis pelo desenvolvimento precoce de vasos de xilema.

\section{Rizogênese}

O desenvolvimento de estruturas rizogênicas foi inversamente proporcional ao tempo de cultivo in vitro, ou seja, no período de 21 dias, a formação de raízes foi mais evidente em comparação aos calos cultivados por 31 dias. Komatsu (1995) relatou a formação de raízes com calos do tipo amarelo globoso ao estudar a morfogênese de Phylostachys bambusoides. Diante do presente estudo, não se verificou essa correlação em calos de E. urophylla.

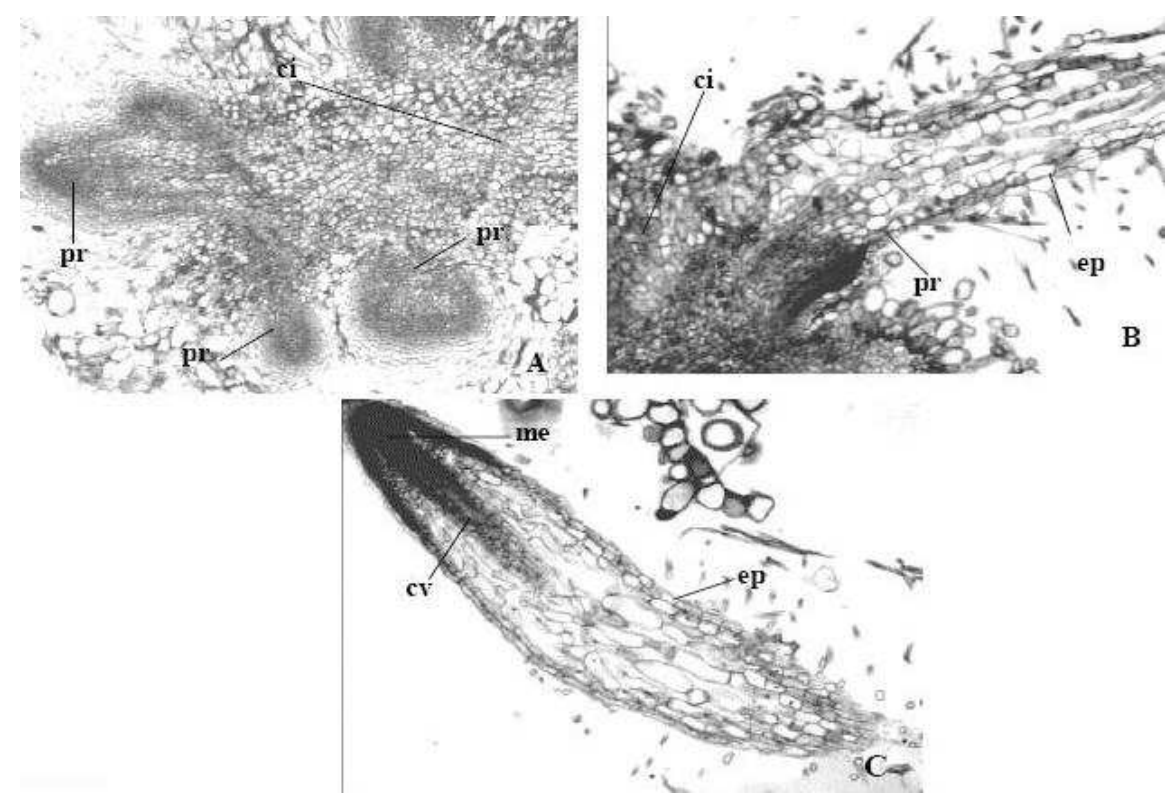

Figura 4. Formação de primórdios radiculares em cortes longitudinais. A. Presença de raízes em início de formação, apresentando desenvolvimento endógeno, denotando uma ligação evidente entre raiz e calo; B. Raiz que rompeu as células internas do calo e despontou na superfície sem perder a conexão inicial; C. Raiz formada com cilindro vascular evidente. pr - primórdio radicial, ci - células indiferenciadas do calo, ep - epiderme da raiz, cv - cilindro vascular, me região meristemática.

Figure 4. Roots primordia development visualized in longitudinal cuts. A. Roots in initial growth presenting endogenous development and showing a clear link between root and callus; B. Root that broke the callus internal cells and emerged in the surface without losing the initial connection; C. Root formed with evident vascular cylinder. pr - root primordia, ci - callus undifferentiated cells, ep - root epidermis, cv - vascular cylinder, me - meristematic region.

Aos 21 dias, as combinações de $25 \mu \mathrm{M}$ de B com 7,50 mM de Ca, $50 \mu \mathrm{M}$ de B com $0 \mathrm{mM}$ de $\mathrm{Ca}$ e $100 \mu \mathrm{M}$ de $\mathrm{B}$ com 7,50 mM de Ca apresentaram ligação mais coesa entre raízes e calos. Esse efeito 
também foi verificado em calos cultivados por 31 dias nos seguintes tratamentos: $0 \mu \mathrm{M}$ de B com 11,25 e $15,00 \mathrm{mM}$ de $\mathrm{Ca}, 25 \mu \mathrm{M}$ de B com 11,25 e 15,00 mM de Ca, $100 \mu \mathrm{M}$ de B com 11,25 mM de Ca e $200 \mu \mathrm{M}$ de B com 7,50; 11,25 e 15,00 mM de Ca (Figuras 4A e 4B).

Independentemente das concentrações de B e dos períodos de análises, verificou-se relação entre a concentração de $\mathrm{Ca}$ e a presença de raízes junto à massa de células. Concentrações de $\mathrm{Ca}$ superiores a 7,50 mM foram mais efetivas nessa resposta, denotando provável interferência de Ca na indução de raízes conectadas à massa de calos. Comparando esses resultados com a anatomia interna dos calos (Figura 4), verifica-se que as raízes desenvolvidas nesses tratamentos surgiram a partir de divisões celulares internas, conectadas à massa de calos mais compactos ou menos friáveis.

As combinações de $0 \mu \mathrm{M}$ de B com 3,75; 7,50; 11,25 e 15,00 mM de Ca, $100 \mu \mathrm{M}$ de B com 0; 3,75 e $15,00 \mathrm{mM}$ de $\mathrm{Ca}$, aos 21 dias de cultivo, apresentaram raízes adventícias sem conexão vascular com o tecido formador, tornando-as facilmente destacadas da massa do calo, que poderiam ter se originado a partir de células mais externas (Figura 4C). Em tratamentos com omissão total de B e Ca não existiu a indução de raízes em nenhum dos períodos analisados.

\section{Biomassa seca}

O boro é um micronutriente importante para espécies do gênero Eucalyptus, e sua deficiência gera o decréscimo em produção de biomassa seca (ROCHA FILHO et al., 1978; SILVEIRA, 1996; SGARBI et al.,1999). Neste trabalho, a produção de biomassa seca foi influenciada pela concentração de boro dentro de cada concentração de cálcio. Foi observado que as concentrações mais elevadas de boro, em todas as concentrações de cálcio, induziram ao menor desenvolvimento em biomassa seca.

$\mathrm{Na}$ avaliação realizada aos 21 dias de cultivo, observou-se que o tratamento com $200 \mu \mathrm{M}$ de B sem $\mathrm{Ca}$ foi o que apresentou menor desenvolvimento, enquanto o tratamento com $50 \mu \mathrm{M}$ de B e 7,50 mM de $\mathrm{Ca}$ foi o que obteve maior biomassa seca. $\mathrm{Na}$ avaliação realizada aos 31 dias, observou-se que o tratamento com $200 \mu \mathrm{M}$ de B e $11,25 \mathrm{mM}$ de Ca foi o que apresentou menor desenvolvimento, enquanto o tratamento com $50 \mu \mathrm{M}$ de B e 7,50 $\mathrm{mM}$ de Ca foi o que obteve maior biomassa seca. Mas, para ambas as idades avaliadas e para todas as concentrações de cálcio estudadas, foi observado que o aumento da dose de boro é benéfica até uma determinada concentração, entre 50 e $100 \mu \mathrm{M}$ de B, sendo que concentrações maiores geram diminuição do desenvolvimento da biomassa seca (Figura 5).

\section{CONCLUSÕES}

- A interação B e Ca determinou mudanças específicas na morfologia externa e interna de calos de Eucalyptus urophylla, tanto aos 21 quanto aos 31 dias de cultivo in vitro.

- Os maiores tamanhos dos calos foram obtidos nas combinações de $50 \mu \mathrm{M}$ de B com 7,50 mM de Ca (21 dias) e no meio N7 (31 dias).

- A avaliação da morfologia interna dos calos revelou a presença de meristemoides e o desenvolvimento precoce de xilema.

- As combinações de $25 \mu \mathrm{M}$ de B com 0; 3,75; 7,50; 11,25 e 15,00 mM de Ca, aos 21 dias, mostraramse menos prejudiciais ao desenvolvimento das raízes.

- A concentração de boro influenciou a produção de biomassa seca dos calos de Eucalyptus urophylla cultivados in vitro.

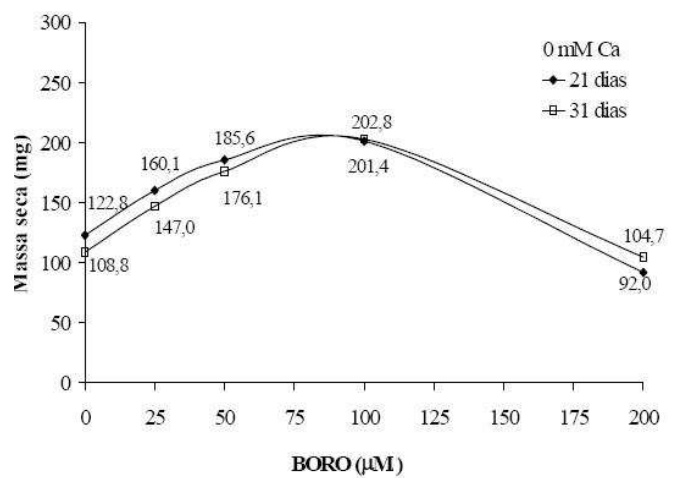

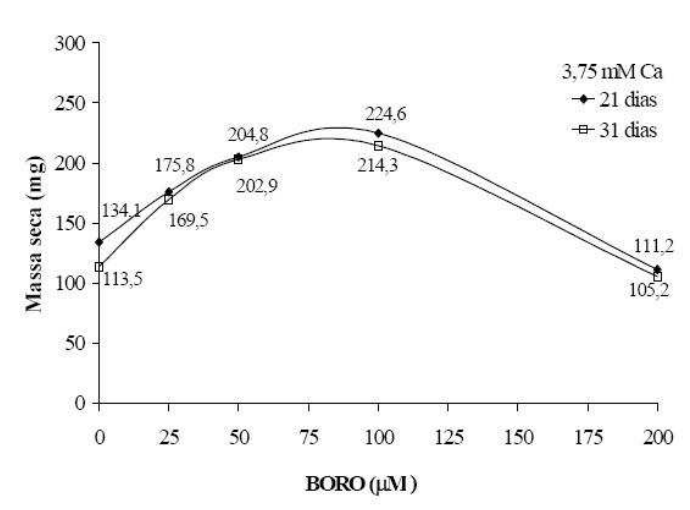

FLORESTA, Curitiba, PR, v. 41, n. 3, p. 563-574, jul./set. 2011. 


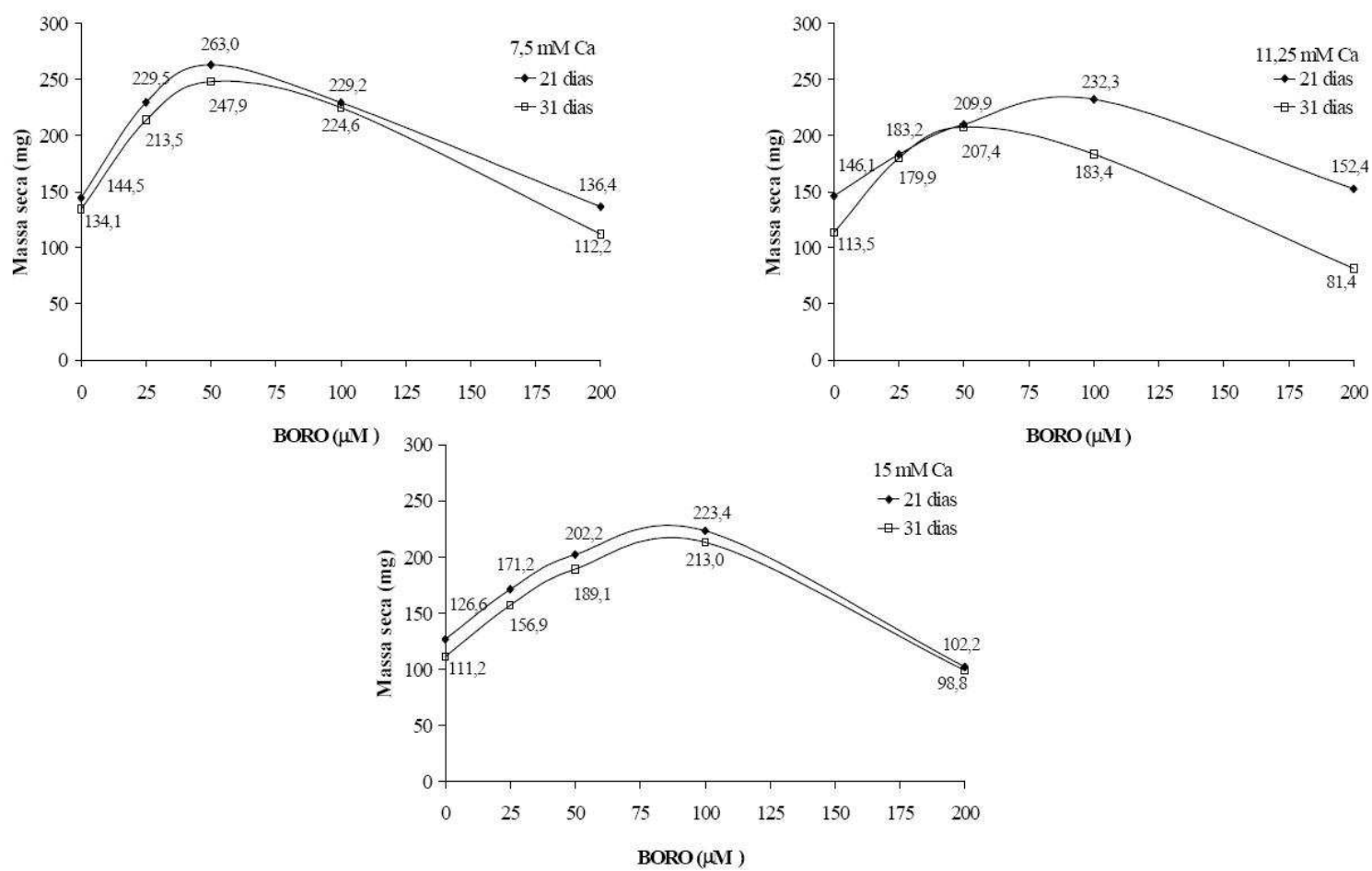

Figura 5. Biomassa seca (mg) dos calos de Eucalyptus urophylla avaliados aos 21 e 31 dias de cultivo in vitro em função de concentrações de boro e de cálcio.

Figure 5. Biomass (mg) of Eucalyptus urophylla callus evaluated at 21 to 31 days, under in vitro cultivation, in function of boron and calcium concentrations.

\section{REFERÊNCIAS}

ALFENAS, A. C.; ZAUZA, E. A. V.; MAFIA, R. G.; ASSIS, T. F. Clonagem e doenças do eucalipto. Viçosa: UFV, 2004. 442 p.

ARRUDA, S. C. C. Efeito do cálcio na indução de embriogênese somática em Eucalyptus urophylla. 73 f. Dissertação (Mestrado em Recursos Florestais) - Escola Superior de Agricultura "Luiz de Queiroz", Universidade de São Paulo, Piracicaba, 2000.

BARROS, N. F.; NEVES, J. C. L.; NOVAIS, R. F. Recomendação de fertilizantes minerais em plantios de eucalipto. In: GONÇALVES, J. L. M.; BENEDETTI, V. (Ed.). Nutrição e fertilização florestal. Piracicaba: IPEF, 2005. p. 269 - 286.

EPSTEIN, E.; BLOOM, A. J. Nutrição mineral de plantas: princípios e perspectivas. Tradução: E. T. Nunes. Londrina: Ed. Planta, 2004. 403 p.

ESAU, K. Anatomia das plantas com sementes. Tradução: B. L. Morretes. São Paulo: Edgard Blücher, 2000. $293 \mathrm{p}$.

GLOCKE, P.; DELAPORTE, K.; COLLINS, G.; SEDGLEY, M. Micropropagation of juvenile tissue of Eucalyptus erythronema x Eucalyptus stricklandii Cv. "Urrbrae Gem". In Vitro Cellular and Developmental Biology-Plant, v. 42, n. 2, p. 139 - 143, 2006.

GONÇALVES, J. L. M.; VALERI, S. V. Eucaliptos e pinus. In: FERREIRA, M. E.; CRUZ, M. C. P.; RAIJ, B. (Ed.). Micronutrientes e elementos tóxicos na agricultura. Jaboticabal: CNPq, FAPESP, POTAFOS, 2001. p. 393 - 423. 
GONÇALVES, J. L. M. Principais solos usados para plantações florestais. In: GONÇALVES, J. L. M.; STAPE, J. L. (Ed.). Conservação e cultivo de solos para plantações florestais. Piracicaba: IPEF, 2002. p. 1 - 45.

GRIBBLE, K.; CONROY, J. P.; HOLFORD, P.; MILHAM, P. J. In vitro uptake of minerals by Gypsophila paniculata and hybrid eucalypts, and relevance to media mineral formulation. Australian Journal of Botany, Collingwood, v. 50, n. 6, p. 713 - 723, 2002.

HO, W.; VASIL, I. K. Somatic embryogenesis in sugarcane (Saccharum officinarum L.) I. The morphology and physiology of callus formation and the ontogeny of somatic embryos. Protoplasma, Karlsruhe, v. 118, n. 3, p. 169 - 180, 1983.

HU, H.; BROWN, P. H. Localization of boron in cell wall of squash and tobacco and its association with pectin. Plant Physiology, Rockville, v. 105, n. 2, p. 681 - 689, 1994.

KARNOVSKY, M. J. A formaldehyde-glutaraldehyde fixative of high osmolality for use in electron microscopy. Journal of Cell Biology, New York, n. 27, p. 137 - 138, 1965.

KOMATSU, H. K. Estudo da morfogênese em calos de Phyllostachys bambusoides Sieb. \& Zucc. 105 p. Tese (Doutorado em Recursos Florestais) - Escola Superior de Agricultura "Luiz de Queiroz", Universidade de São Paulo, Piracicaba, 1995.

LEWIS, D. H. Boron, lignification and origin of vascular plants - a unified hypothesis. New Phytologyst, Cambridge, v. 84, p. 209 - 229, 1980.

MALAVOLTA, E. Elementos de nutrição mineral de plantas. São Paulo: Ceres, 1980. 251 p.

MARSCHNER, H. Mineral nutrition of higher plants. 2. ed. London: Academic Press, 1995. 889 p.

MATOH, T.; ISHIGAKI, K. I.; MIZUTANI, M.; MATSUNAGA, W.; TAKABE, K. Boron nutrition of cultured tobacco BY-2 cells. I. Requirement for intracellular localization of boron and selection of cell that tolerant low level of boron. Plant Cell Physiology, Oxford, v. 33, n. 8, p. 1135 - 1141, 1992.

MORAES, L. A. C.; MORAES, V. H. F.; MOREIRA, A. Relação entre a flexibilidade do caule de seringueira e a carência de boro. Pesquisa Agropecuária Brasileira, Brasília, v. 37, n. 10, p. 1431 - 1436, 2002.

MURASHIGE, T.; SKOOG, F. A revised medium for rapid growth and bioassays with tobacco tissue cultures. Physiologia Plantarum, Kopenhagen, v. 15, p. 473 - 497, 1962.

NEHRA, N. S.; BECWAR, M. R.; ROTTMANN, W. H.; PEARSON, L.; CHOWDHURY, K.; CHANG, S.; WILDE, H. D.; KODRZYCKI, R. J.; ZHANG, C.; GAUSE, K. C.; PARKS, D. W.; HINCHEE, M. A. Invited review: forest biotechnology: innovative methods, emerging opportunities. In Vitro Cellular and Developmental Biology-Plant, v. 41, n. 6, p. 701 - 717, 2005.

ROCHA FILHO, J. V.; HAAG, H. P.; OLIVEIRA, G. D. Deficiência de macronutrientes, boro e ferro em Eucalyptus urophylla. Anais da Escola Superior de Agricultura "Luiz de Queiroz", Piracicaba, v. 35, n. 35, p. 19 - 34, 1978.

SAKAI, W. S. Simple method for differential staining of parafilm embedded plant material using toluidine blue 01. Stain Technology, Baltimore, v. 48, n. 5, p. 247 - 249, 1973.

SGARBI, F.; SILVEIRA, R. L. V. A.; TAKAHASHI, E. N.; CAMARGO, M. A. F. Crescimento e produção de biomassa de clone de Eucalyptus grandis x Eucalyptus urophylla em condições de deficiência de macronutrientes, B e Zn. Scientia Forestalis, Piracicaba, n. 56, p. 69 - 82, 1999.

SILVEIRA, R. L. V. A. Crescimento e estado nutricional de Eucalyptus citriodora sob concentrações de B e sua relação com agressividade de Botryosphaeria ribis. 100 f. Dissertação (Mestrado em Solos e Nutrição de Plantas) - Escola Superior de Agricultura "Luiz de Queiroz", Universidade de São Paulo, Piracicaba, 1996.

SIMOLA, L. K. Propagation of plantets from leaf callus of Betula pendula f. purpurea. Scientia Horticulturae, Amsterdam, v. 26, n. 1, p. 77 - 85, 1985. 
SPURR, A. R. The effect of boron on cell walls structure in celery. American Journal of Botany. Davis, v. 44, p. $637-650,1957$.

TAIZ, L.; ZEIGER, E. Fisiologia vegetal. Tradução: E. R. Santarém et al. 3. ed. Porto Alegre: Artmed, 2004. $719 \mathrm{p}$.

TREVIZAM, R. Atuação de concentrações de boro na morfogênese de Eucalyptus urophylla cultivados in vitro. 65 f. Dissertação (Mestrado em Recursos Florestais) - Escola Superior de Agricultura "Luiz de Queiroz", Universidade de São Paulo, Piracicaba, 2001.

WATT, M. P.; THOKOANE, N. L.; MYCOCK, D.; BLAKEWAY, F. In vitro storage of Eucalyptus grandis germplasm under minimal growth conditions. Plant Cell, Tissue and Organ Culture, Netherlands, v. 61, n. 2, p. $161-164,2000$. 
FLORESTA, Curitiba, PR, v. 41, n. 3, p. 563-574, jul./set. 2011.

Trevizam, R. et al. 